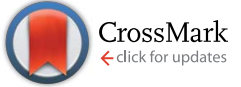

Cite this: RSC Adv., 2017, 7, 6720

Received 2nd December 2016 Accepted 10th January 2017

DOI: $10.1039 / c 6 r a 27690 c$

www.rsc.org/advances

\section{Synthesis and characterization of titanium(Iv)/ graphene oxide foam: a sustainable catalyst for the oxidation of benzyl alcohol to benzaldehyde $\uparrow$}

\author{
Wenxi Ma, Qiaoling Tong, Jian Wang, Huali Yang, Meng Zhang, Hailun Jiang, \\ Qinghe Wang, * Yongxiang Liu* and Maosheng Cheng*
}

A sustainable catalyst for the selective oxidation of benzyl alcohol $(\mathrm{BnOH})$ to benzaldehyde $(\mathrm{BzH})$ was developed by mineralizing $\mathrm{Ti}\left(\mathrm{SO}_{4}\right)_{2}$ on graphene oxide foam (GOF) surface. The $\mathrm{Ti}\left(\mathrm{SO}_{4}\right)_{2} / \mathrm{GOF}$ was characterized by scanning electron microscopy (SEM), energy disperse spectroscopy (EDS), $X$-ray diffraction (XRD), solid-state NMR (SSNMR), thermal gravimetric analysis (TGA), infrared (IR) and BET analysis. Recycling experiments proved that $\mathrm{Ti}\left(\mathrm{SO}_{4}\right)_{2} / \mathrm{GOF}$ possessed excellent reusability and durability. The industrial perspective of $\mathrm{Ti}\left(\mathrm{SO}_{4}\right)_{2} / \mathrm{GOF}$ was demonstrated by the preparation of $\mathrm{BzH}$ in a large-scale and solvent-free oxidation process.
The market demand of $\mathrm{BzH}$ as a valuable precursor for the production of pharmaceuticals, herbicides and spices, is huge every year, especially in developing countries. The oxidation of $\mathrm{BnOH}$ is one of major methods to obtain $\mathrm{BzH}$. Traditionally, oxidation of $\mathrm{BnOH}$ to $\mathrm{BzH}$ was performed with stoichiometric amounts of chromium(vi) reagents, which were harmful to the environment due to the generation of copious amounts of heavy-metal and chlorine-containing wastes. In recent years, a lot of novel methods have been developed, such as photocatalysis, ${ }^{1}$ crystalline noble-metal oxide catalysis, ${ }^{2}$ electrocatalysis, ${ }^{3}$ metal-free method ${ }^{4}$ and noble metal nanocomposite catalysis. ${ }^{5}$ In addition, some green chemistry strategies such as oxidation processed in ionic liquids ${ }^{6}$ and under microwave irradiated conditions have also been developed. ${ }^{7}$ However, the methods mentioned above have several problems including low conversion or selectivity ${ }^{10, d, 8}$ complex synthesis processes of the catalysts, ${ }^{2,3}$ demanding a cocatalyst, ${ }^{4}$ unrecyclable metals, ${ }^{1 c}$ the high cost of noble metals ${ }^{5 c, d, 8}$ and serious environmental problems caused by heavy-metal wastes.

Graphene oxide (GO), was obtained by the oxidation of graphite and subsequent exfoliation of the carbon sheets by ultrasonic irradiation in water after dried in vacuo. ${ }^{9}$ Alternative freeze-drying treatment process would generate spongy graphene oxide foam (GOF). ${ }^{9}$ Various oxygen-containing groups may generate on GO or GOF surface and edge during oxidation

Key Laboratory of Structure-Based Drug Design and Discovery (Shenyang Pharmaceutical University), Ministry of Education, Shenyang 110016, P. R. China. E-mail: qinghe-wang@163.com; yongxiang.liu@syphu.edu.cn; mscheng@syphu.edu. cn

$\dagger$ Electronic supplementary information (ESI) available: General procedures, large-scaled synthesis of BzH under solvent-free condition, recycling tests of $\mathrm{Ti}\left(\mathrm{SO}_{4}\right)_{2} / \mathrm{GOF}$. See DOI: $10.1039 / \mathrm{c} 6 \mathrm{ra} 27690 \mathrm{c}$ process. ${ }^{4}$ Many astonishing chemical properties of GO are resulted from the functional groups, which can reduce the activation energy and increase the selectivity of reactions, ${ }^{5 a, 10}$ supply different chemical decoration sites, ${ }^{11}$ and also be reduced to reduced $\mathrm{GO}(\mathrm{rGO})$ leading to the reconstruction of $\mathrm{sp}^{2}$ hybridized carbon atoms. ${ }^{11 c}$ Many efforts have been made on the GO-based oxidation of $\mathrm{BnOH}$ into $\mathrm{BzH}$, which include rGO-metal composites-catalyzed oxidation, ${ }^{5 b}$ photocatalysis oxidation based on GO skeleton, ${ }^{1 a, d}$ and GO-involved electrocatalysis oxidation. ${ }^{12}$ More sustainable and robust oxidation process is still urgent in the further development of GO-based methodologies.

Titanium sulfate $\left[\mathrm{Ti}\left(\mathrm{SO}_{4}\right)_{2}\right]$ is a cheap water soluble inorganic titanium with low toxicity and abundant natural reserves. It has been widely used in the preparation of titanium dioxide an important semiconductor and photosensitive material. ${ }^{13}$ Many studies were focused on the use of $\mathrm{Ti}\left(\mathrm{SO}_{4}\right)_{2}$ as a precursor to prepare nano $\mathrm{TiO}_{2}$ and the exploration of its photocatalytic properties. However, there were fewer studies on the catalytic properties for its inherent instability to moisture and the insolubility in most organic solvents. To explore the inherent catalytic properties of $\mathrm{Ti}\left(\mathrm{SO}_{4}\right)_{2}$, we planned to mineralize $\mathrm{Ti}\left(\mathrm{SO}_{4}\right)_{2}$ on the surface of GOF to improve its ability in catalyzing reactions. We assumed that the use of GOF as a carrier to immobilize $\mathrm{Ti}\left(\mathrm{SO}_{4}\right)_{2}$ through the carboxyl groups on GOF edge could prevent metal ions to hydrolyze and could make the $\mathrm{Ti}\left(\mathrm{SO}_{4}\right)_{2}$ well dispersed on its matrix to ensure supplying more catalytic sites and recovering from reaction system. Moreover, the highly dispersed $\mathrm{Ti}^{4+}$ will contribute to adsorb $\mathrm{BnOH}$ on its surface by the interaction between hydroxyl group and $\mathrm{Ti}^{4+}$. On the other hand, various oxygen-containing groups on GO surface can interact with $\mathrm{BnOH}$ and $\mathrm{H}_{2} \mathrm{O}_{2}$ through 
intermolecular hydrogen bonds, which promote the oxidation of $\mathrm{BnOH}$ on the $\mathrm{Ti}\left(\mathrm{SO}_{4}\right)_{2}$ surface. Finally, we succeeded in mineralizing $\mathrm{Ti}\left(\mathrm{SO}_{4}\right)_{2}$ on the GOF surface, characterizing the new GOF-Ti(Iv) complex by various spectroscopy and developing an environmentally friendly and sustainable method to oxidize $\mathrm{BnOH}$ to $\mathrm{BzH}$. It is worthy to mention that the solvent and catalyst are recyclable and water is the only by-product for the process.

Our research began by the preparation of GO using modified Offeman's protocol. ${ }^{\mathbf{1 4}}$ As-synthesized graphite oxide was dispersed in the aqueous solution of $\mathrm{Ti}\left(\mathrm{SO}_{4}\right)_{2}$ and put under the ultrasonic irradiation for 1 hour followed by freeze drying leading to $\mathrm{Ti}\left(\mathrm{SO}_{4}\right)_{2} / \mathrm{GOF}$. Scanning electron microscope (SEM) and energy disperse spectroscopy (EDS) patterns demonstrated that $\mathrm{Ti}\left(\mathrm{SO}_{4}\right)_{2}$ was distributed on the surface of GOF with $\mu \mathrm{M}$ size. Two types of crystal morphology were observed in the material, in which loosen structure was anchored on the edge and center depressed area and 'branch-like' structure was paved on GOF sheets (Fig. 1).

X-ray diffraction (XRD) pattern showed that the $\mathrm{Ti}\left(\mathrm{SO}_{4}\right)_{2}$ mineralized on GOF surface was amorphous crystal (Fig. 2). Diffraction peaks at $10^{\circ}$ to $30^{\circ}$ are amorphous peaks. What's more, no significant change was observed when it was reused 10 times for the oxidation, which will be introduced in details in the following applications. From the curves 1-3 in Fig. 2, it can be seen that pure amorphous $\mathrm{Ti}\left(\mathrm{SO}_{4}\right)_{2}$ showed only one peak, but the peak position shifted a little and split into two peaks in fresh $\mathrm{Ti}\left(\mathrm{SO}_{4}\right)_{2} / \mathrm{GOF}$. We conjectured that this was caused by the interaction between $\mathrm{Ti}\left(\mathrm{SO}_{4}\right)_{2}$ and the different oxygencontaining groups on the surface of GOF during mineralization process.

To prove the interaction between $\mathrm{Ti}\left(\mathrm{SO}_{4}\right)_{2}$ and GOF, the IR studies were performed. As indicated in Fig. 3, the absorption peak of ether/epoxide (C-O-C, green band) vanished in $\mathrm{Ti}\left(\mathrm{SO}_{4}\right)_{2} /$ $\mathrm{GOF}$, meanwhile, a new peak appeared in the fingerprint region $\left(\sim 600 \mathrm{~cm}^{-1}\right)$. This result directly proved the presence of titaniumoxygen coordination. ${ }^{15}$ Intriguingly, the absorption peak of phenolic hydroxyl (C-OH, 2000-3600 $\mathrm{cm}^{-1}$, blue bond) did not show any change at all. This phenomenon indicates that the
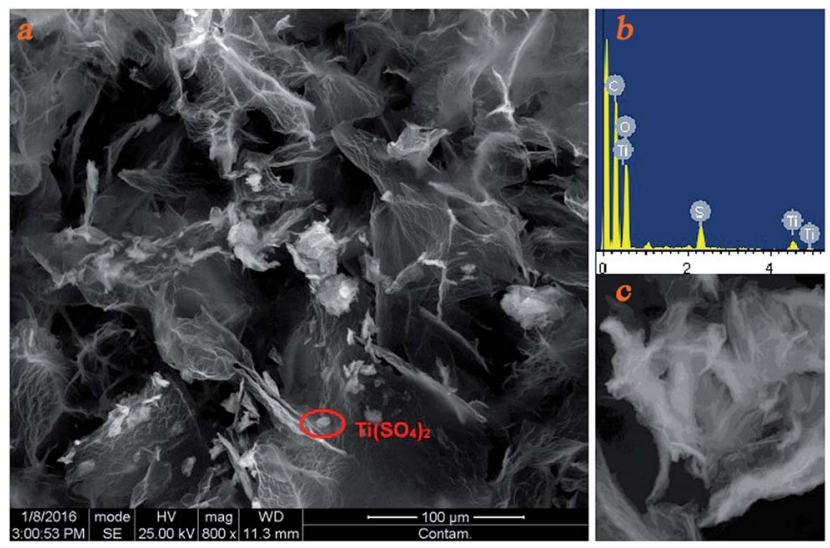

Fig. 1 The morphology of $\mathrm{Ti}\left(\mathrm{SO}_{4}\right)_{2} / \mathrm{GOF}$. (a) SEM spectroscopy of fresh $\mathrm{Ti}\left(\mathrm{SO}_{4}\right)_{2} / \mathrm{GOF}$; (b) EDS; (c) magnification of selected area in the left picture.

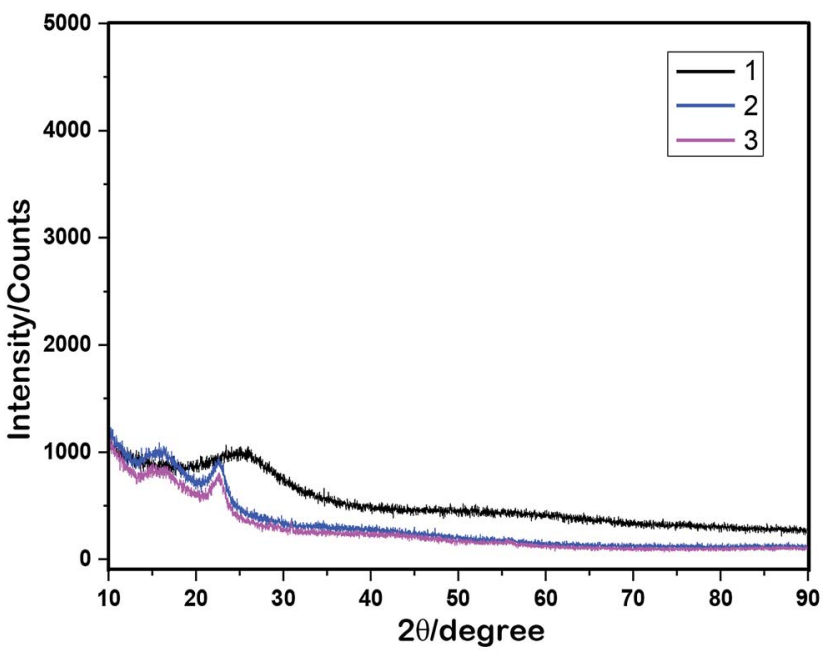

Fig. 2 Powder XRD patterns. Curve 1: amorphous Ti( $\left(\mathrm{SO}_{4}\right)_{2}$. Curve 2: fresh $\mathrm{Ti}\left(\mathrm{SO}_{4}\right)_{2} / \mathrm{GOF}$. Curve 3: recycled 10 times $\mathrm{Ti}\left(\mathrm{SO}_{4}\right)_{2} / \mathrm{GOF}$.

$\mathrm{Ti}\left(\mathrm{SO}_{4}\right)_{2}$ prefers to interact with ether/epoxide, rather than hydroxyl. The ether/epoxide belongs to the electrophilic oxygen species on carbon matrix. ${ }^{10 b}$ Spin-trapping electron paramagnetic resonance (EPR) proved that the radicals generated from zigzagedge could activate oxygen, ${ }^{\mathbf{1 6}}$ meanwhile, the carbon skeleton exhibited the nature of 'Frustrated Lewis Pairs (FLP)'. ${ }^{9}$ Moreover, the radicals can be delocalized through carbon matrix as 'passageway'.,16 These evidences indicate that the ether/epoxide can be activated by radicals. Therefore, we speculated that the radicals could immigrate from carbon skeleton to ether/epoxide, which activated the unshared pair electrons of oxygen to interact with titanium. Thus, the ether/epoxide seems likely 'oxygencontaining solid carbene'.

To gain an insight into the interaction between $\mathrm{Ti}\left(\mathrm{SO}_{4}\right)_{2}$ and GOF, the ${ }^{13} \mathrm{C}-\mathrm{SSNMR}$ measurement was performed (Fig. 4). Unlike IR spectrum, the ${ }^{13} \mathrm{C}-\mathrm{SSNMR}$ spectra revealed a series of

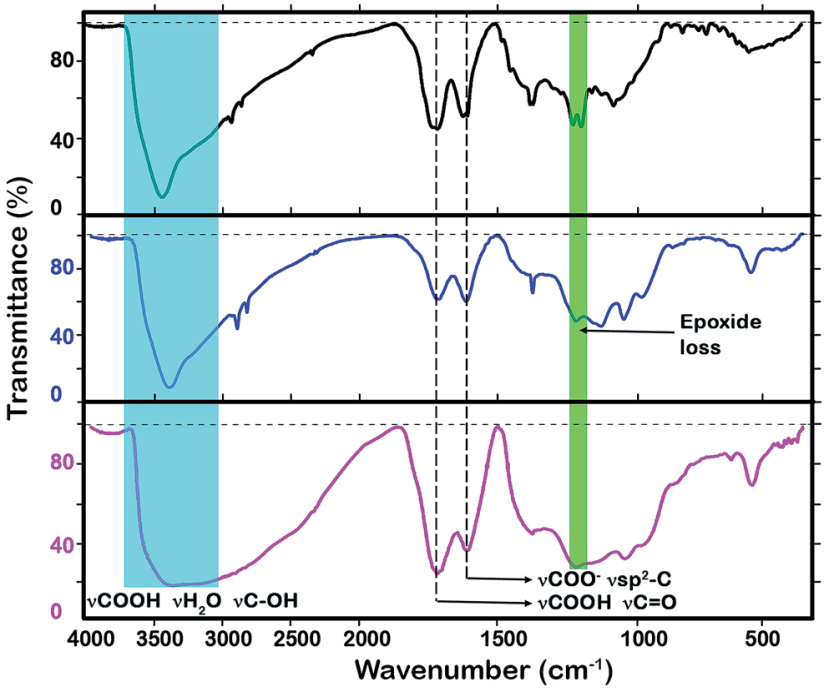

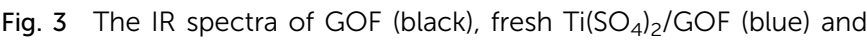
recycled $\mathrm{Ti}\left(\mathrm{SO}_{4}\right)_{2} / \mathrm{GOF}$ (pink) with $\mathrm{KBr}$ tablet. 
significant decrease at $61.5 \mathrm{ppm}(\mathrm{C}-\mathrm{O}-\mathrm{C}), 71.0 \mathrm{ppm}(\mathrm{C}-\mathrm{OH})$ and $125.6 \mathrm{ppm}$ (graphitic $\mathrm{sp}^{2}$-C) in freshly prepared $\mathrm{Ti}\left(\mathrm{SO}_{4}\right)_{2} / \mathrm{GOF}$. In $\mathrm{TiO}_{2}$ crystal, $\mathrm{Ti}^{4+}$ defective sites will lead to generate ferromagnetism at room temperature. ${ }^{17}$ We inferred that this was caused by $\mathrm{Ti}^{4+}$ defective sites in $\mathrm{Ti}\left(\mathrm{SO}_{4}\right)_{2}$ crystal leading to ferromagnetism which depressed ${ }^{13} \mathrm{C}-\mathrm{SSNMR}$ signals. However, it was observed that the signals of $\mathrm{C}-\mathrm{O}-\mathrm{C}$, graphitic $\mathrm{sp}^{2}-\mathrm{C}$ and $\mathrm{O}=\mathrm{C}-\mathrm{O}$ were recovered again when the catalyst was reused for 10 times. SEM spectroscopy has shown that the $\mathrm{Ti}\left(\mathrm{SO}_{4}\right)_{2}$ will exfoliate off from the carbon skeleton after recycled 10 times, which will increase the ${ }^{13} \mathrm{C}$-SSNMR signals (see ESI $\dagger$ ). Moreover, the intensity of $\mathrm{O}=\mathrm{C}-\mathrm{O}$ increased apparently, which may be caused by the formation of esters and anhydrides of the carboxyl groups on carbon sheets. In addition, the IR spectra indicated that the absorption peaks of $\mathrm{COOH}$ and $\mathrm{C}-\mathrm{OH}$ became broader after 10 times reuses. Meanwhile, the BET analysis showed obvious decrease of the surface area in the catalyst recycled 10 times (Table 1). These results showed that the interlayer spacing among carbon sheets decreased apparently in the recycled catalyst. Besides, the thermal stabilities of fresh and reused $\mathrm{Ti}\left(\mathrm{SO}_{4}\right)_{2} / \mathrm{GOF}$ were affected by the amounts of esters and anhydrides.

The thermal stability of the fresh and recycled $\mathrm{Ti}\left(\mathrm{SO}_{4}\right)_{2} / \mathrm{GOF}$ was studied on the basis of simple TGA experiments. Fig. 5 displayed the TGA thermograms of GOF, fresh and recycled for 10 times $\mathrm{Ti}\left(\mathrm{SO}_{4}\right)_{2} / \mathrm{GOF}$ for the oxidation of $\mathrm{BnOH}$ in nitrogen atmosphere. We found that $\mathrm{Ti}\left(\mathrm{SO}_{4}\right)_{2} / \mathrm{GOF}$ displayed different thermal stability below and beyond $200{ }^{\circ} \mathrm{C}$. Our experiments showed that the thermal decomposition of GOF was fastest at $200{ }^{\circ} \mathrm{C}$, which was consistent with previous report on the thermal stability of GO. ${ }^{18}$ The result indicated that the GOF and GO had the same thermal stability although they showed different physical forms. The rate of weight loss was different in fresh and recycled $\mathrm{Ti}\left(\mathrm{SO}_{4}\right)_{2} / \mathrm{GOF}$. The rate of weight loss in fresh $\mathrm{Ti}\left(\mathrm{SO}_{4}\right)_{2} / \mathrm{GOF}$ was fastest at $150{ }^{\circ} \mathrm{C}$, while that in reused

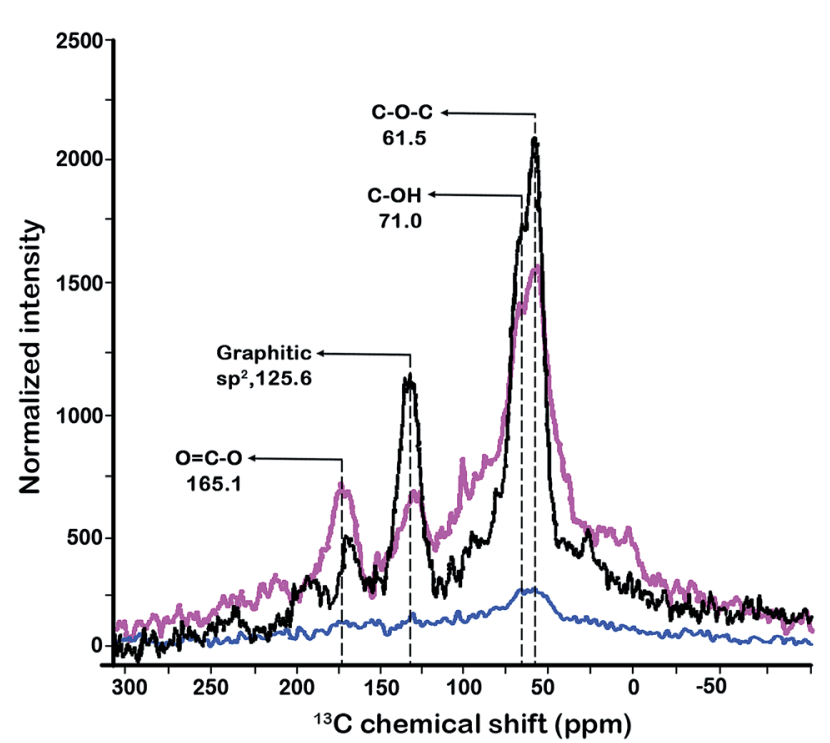

Fig. $4{ }^{13} \mathrm{C}$-SSNMR spectra of GOF (black), fresh Ti( $\left(\mathrm{SO}_{4}\right)_{2} / \mathrm{GOF}$ (blue) and recycled $\mathrm{Ti}\left(\mathrm{SO}_{4}\right)_{2} / \mathrm{GOF}$ (pink). (Direct ${ }^{13} \mathrm{C}$ onepulse, ro $=4.0 \mathrm{kHz}$.)
Table 1 BET analysis

\begin{tabular}{lll}
\hline Catalyst & $\begin{array}{l}\text { Correlation } \\
\text { coefficient }\end{array}$ & Surface area \\
\hline Fresh & 0.9996 & $119.8 \mathrm{~m}^{2} \mathrm{~g}^{-1}$ \\
Recycled & 0.9995 & $19.8 \mathrm{~m}^{2} \mathrm{~g}^{-1}$ \\
\hline
\end{tabular}

$\mathrm{Ti}\left(\mathrm{SO}_{4}\right)_{2} / \mathrm{GOF}$ was fastest at $200{ }^{\circ} \mathrm{C}$ correspondingly. The carboxyl group would decompose from $150{ }^{\circ} \mathrm{C}$ to $200^{\circ} \mathrm{C}$ and the esters and anhydrides would begin to decompose when the temperature was beyond $200{ }^{\circ} \mathrm{C}^{18}$ Therefore, the dehydration of carboxyl and hydroxyl groups will occur along with the increase of use times.

Next, the obtained catalyst was examined in the oxidation of $\mathrm{BnOH}$ to BzH. The screening of reaction conditions was summarized in Table 2. Blank experiment showed that the conversion of $\mathrm{BnOH}$ was only $6.1 \%$ in the absence of catalyst (Table 2, entry 1). However, the conversion of $\mathrm{BnOH}$ rose to $70.2 \%$ and the selectivity to $\mathrm{BzH}$ was increased to $99 \%$ when $\mathrm{Ti}\left(\mathrm{SO}_{4}\right)_{2} / \mathrm{GOF}$ was used (Table 2, entry 2). Extension of reaction time had little influence on the conversion of $\mathrm{BnOH}$ (Table 2, entry 3). We failed to improve the conversion after tried different methods such as increase of the amount of $\mathrm{H}_{2} \mathrm{O}_{2}$ and $\mathrm{Ti}\left(\mathrm{SO}_{4}\right)_{2} / \mathrm{GOF}$, addition of radical initiator, adjustion of the $\mathrm{pH}$ value and slow addition of $\mathrm{H}_{2} \mathrm{O}_{2}$ (Table 2, entries 4-8). Examination of solvent effect proved that THF was the optimal solvent, which afforded $88.9 \%$ conversion with $99 \%$ selectivity to BzH (Table 2, entries 9-11). It is important to notice that $\mathrm{MeOH}$, the solvent we screened in the condition can't be oxidized in this mild condition. Precedent studies showed that the oxidation of $\mathrm{MeOH}$ was carried out at $300-400{ }^{\circ} \mathrm{C}$ using oxygen as the oxidant. ${ }^{19} \mathrm{We}$ rationalized that THF as the optimal solvent can form intermolecular hydrogen bonds with $\mathrm{H}_{2} \mathrm{O}_{2}$, which prevent $\mathrm{H}_{2} \mathrm{O}_{2}$ to decompose by slow release of $\mathrm{H}_{2} \mathrm{O}_{2}$ into reaction system. Besides, aggregation of the catalyst was observed in acetonitrile and acetone. The influence of the amount of $\mathrm{H}_{2} \mathrm{O}_{2}$ was checked in THF and the best result was obtained when 3.0 eq. $\mathrm{H}_{2} \mathrm{O}_{2}$ was utilized (Table 2, entries 1218). From the results we inferred that the rates of oxidation of $\mathrm{BnOH}$ and $\mathrm{H}_{2} \mathrm{O}_{2}$ decomposition were affected by the concentration of $\mathrm{H}_{2} \mathrm{O}_{2}$. Consequently, the conversion of $\mathrm{BnOH}$ is nonlinearly related with the amount of $\mathrm{H}_{2} \mathrm{O}_{2}$.

The reusability and durability of the catalyst are critical aspects to evaluate the value of industrial application in heterogeneous catalysis. We attempted to recycle $\mathrm{Ti}\left(\mathrm{SO}_{4}\right)_{2} / \mathrm{GOF}$ by

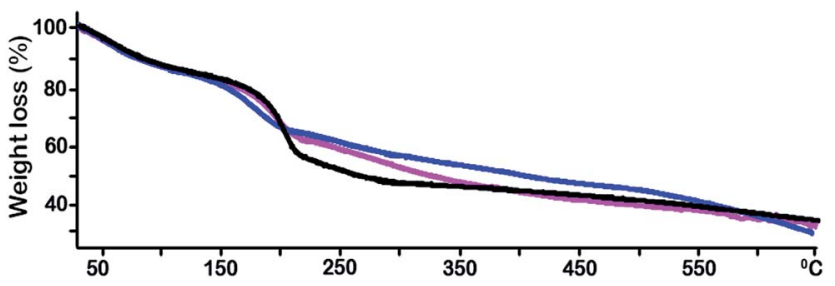

Fig. 5 Thermal gravimetry of GOF (black), fresh Ti( $\left.\mathrm{SO}_{4}\right)_{2} / \mathrm{GOF}$ (blue) and recycled 10 times $\mathrm{Ti}\left(\mathrm{SO}_{4}\right)_{2} / \mathrm{GOF}$ (pink). 
Table 2 Oxidation of $\mathrm{BnOH}$ to $\mathrm{BzH}$ in different conditions

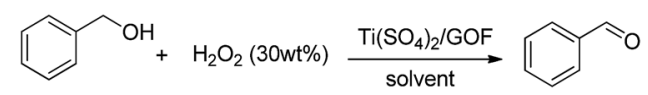

\begin{tabular}{llllll}
\hline Entry $^{a}$ & Reaction time (h) & Solvent & $\mathrm{H}_{2} \mathrm{O}_{2}$ & Con. (\%) & Sel. (\%) \\
\hline 1 & 1 & $\mathrm{MeOH}$ & 1.2 eq. & 6.1 & - \\
2 & 1 & $\mathrm{MeOH}$ & 1.2 eq. & 70.2 & $>99$ \\
3 & 3 & $\mathrm{MeOH}$ & 1.2 eq. & 74.3 & $>99$ \\
4 & 3 & $\mathrm{MeOH}$ & 2.0 eq. & 74.8 & 98.8 \\
$5^{b}$ & 3 & $\mathrm{MeOH}$ & 2.0 eq. & 74.8 & 98.6 \\
$6^{c}$ & 3 & $\mathrm{MeOH}$ & 2.0 eq. & 76.7 & 98.6 \\
$7^{d}$ & 3 & $\mathrm{MeOH}$ & 1.2 eq. & 75.1 & 97.6 \\
$8^{e}$ & 3 & $\mathrm{MeOH}$ & 2.0 eq. & 75.9 & $>99$ \\
9 & 3 & $\mathrm{CH} \mathrm{CN}_{3}$ & 1.2 eq. & 68.1 & $>99$ \\
10 & 3 & $\mathrm{THF}$ & 1.2 eq. & 88.9 & $>99$ \\
11 & 3 & $\mathrm{CH} \mathrm{COCH}_{3}$ & 1.2 eq. & 64.8 & - \\
12 & 4 & $\mathrm{THF}$ & 1.0 eq. & 85.5 & $>99$ \\
13 & 4 & $\mathrm{THF}$ & 2.0 eq. & 88.9 & $>99$ \\
14 & 4 & $\mathrm{THF}$ & 3.0 eq. & 91.3 & 99.0 \\
15 & 4 & $\mathrm{THF}$ & 3.5 eq. & 83.2 & 99.0 \\
16 & 4 & $\mathrm{THF}$ & 4.0 eq. & 91.5 & 98.8 \\
17 & 4 & $\mathrm{THF}$ & 5.0 eq. & 47.2 & - \\
18 & 4 & $\mathrm{THF}$ & 6.0 eq. & 91.5 & 98.4
\end{tabular}

${ }^{a}$ Reaction conditions: $\mathrm{BnOH}(720 \mathrm{mg}, 6.66 \mathrm{mmol}), \mathrm{Ti}\left(\mathrm{SO}_{4}\right)_{2} / \mathrm{GOF}(400$ $\mathrm{mg})$, solvent $(10 \mathrm{~mL})$ and $30 \mathrm{wt} \% \mathrm{H}_{2} \mathrm{O}_{2}(0.82 \mathrm{~mL}, 8.0 \mathrm{mmol})$ under reflux condition. ${ }^{b} 2.0$ eq. of $\mathrm{H}_{2} \mathrm{O}_{2}(30 \mathrm{wt} \%)$ was slowly dropped in $0.5 \mathrm{~h} .{ }^{c} 800 \mathrm{mg} \mathrm{Ti}\left(\mathrm{SO}_{4}\right)_{2} / \mathrm{GOF}$ was applied. ${ }^{d} 0.1 \mathrm{~mol} \%$ benzoyl peroxide was added into reaction system. ${ }^{e} \mathrm{CH}_{3} \mathrm{COOH}$ was added to adjust $\mathrm{pH}$ to 4 .

filtration and use it in the oxidation of $\mathrm{BnOH}$ to $\mathrm{BzH}$ to examine the reusability and durability of the catalyst. To our delight, the result showed that the catalyst could be reused for more than ten times without significant loss of efficiency and selectivity (see Table S1 $\dagger$ ). In addition, the oxidation could also be performed under solvent-free condition in a large scale (see ESI $\dagger$ ).

In conclusion, $\mathrm{Ti}\left(\mathrm{SO}_{4}\right)_{2} / \mathrm{GOF}$ showed unique catalytic activity and chemical selectivity for the oxidation of $\mathrm{BnOH}$ to $\mathrm{BzH}$. The reusability and durability test of the catalyst proved that it possessed excellent chemical stability and could be recycled facilely, which demonstrated promising industrial respective. In addition, the preliminary studies on the interaction between $\mathrm{Ti}\left(\mathrm{SO}_{4}\right)_{2}$ and oxygen functional groups of GOF basal plane were performed, which contributed to understand the intrinsic characters of GOF deeply.

\section{Notes and references}

1 (a) W. Song, A. K. Vannucci, B. H. Farnum, A. M. Lapides, M. K. Brennaman, B. Kalanyan, L. Alibabaei, J. J. Concepcion, M. D. Losego, G. N. Parsons and T. J. Meyer, J. Am. Chem. Soc., 2014, 136, 9773; (b) W. Feng, G. Wu, L. Li and N. Guan, Green Chem., 2011, 13, 3265; (c) C. Meng, K. Yang, X. Fu and R. Yuan, ACS Catal., 2015, 5, 3760; (d) J. Xu, L. Luo, G. Xiao, Z. Zhang, H. Lin, X. Wang and J. Long, ACS Catal., 2014, 4, 3302; (e) M.-Q. Yang, N. Zhang and Y.-J. Xu, ACS Appl. Mater. Interfaces, 2013, 5,
1156; $(f)$ M. Alfè, D. Spasiano, V. Gargiulo, G. Vitiello, R. Di Capua and R. Marotta, Appl. Catal., A, 2014, 487, 91.

2 K. Amakawa, Y. V. Kolen'ko, A. Villa, M. E. Schuster, L.-I. Csepei, G. Weinberg, S. Wrabetz, R. Naumann d'Alnoncourt, F. Girgsdies, L. Prati, R. Schlögl and A. Trunschke, ACS Catal., 2013, 3, 1103.

3 A. K. Vannucci, J. F. Hull, Z. Chen, R. A. Binstead, J. J. Concepcion and T. J. Meyer, J. Am. Chem. Soc., 2012, 134, 3972.

4 G. Lv, H. Wang, Y. Yang, T. Deng, C. Chen, Y. Zhu and X. Hou, ACS Catal., 2015, 5, 5636.

5 (a) L. Shao, X. Huang, D. Teschner and W. Zhang, ACS Catal., 2014, 4, 2369; (b) J. Wang, S. A. Kondrat, Y. Wang, G. L. Brett, C. Giles, J. K. Bartley, L. Lu, Q. Liu, C. J. Kiely and G. J. Hutchings, ACS Catal., 2015, 5, 3575; (c) V. R. Choudhary, A. Dhar, P. Jana, R. Jha and B. S. Uphade, Green Chem., 2005, 7, 768; (d) V. R. Choudhary, R. Jha and P. Jana, Green Chem., 2007, 9, 267.

6 K. R. Seddon and A. Stark, Green Chem., 2002, 4, 119.

7 (a) M. H. C. L. Dressen, J. E. Stumpel, B. H. P. van de Kruijs, J. Meuldijk, J. A. J. M. Vekemans and L. A. Hulshof, Green Chem., 2009, 11, 60; (b) H. Chen, Q. Tang, Y. Chen, Y. Yan, C. Zhou, Z. Guo, X. Jia and Y. Yang, Catal. Sci. Technol., 2013, 3, 328.

8 Y. Hong, X. Jing, J. Huang, D. Sun, T. Odoom-Wubah, F. Yang, M. Du and Q. Li, ACS Sustainable Chem. Eng., 2014, 2, 1752.

9 S. Navalon, A. Dhakshinamoorthy, M. Alvaro and H. Garcia, Chem. Rev., 2014, 114, 6179.

10 (a) B. Frank, J. Zhang, R. Blume, R. Schlögl and D. S. Su, Angew. Chem., Int. Ed., 2009, 48, 6913; (b) B. Zhong, H. Liu, X. Gu and D. S. Su, ChemCatChem, 2014, 6, 1553.

11 (a) S. Eigler and A. Hirsch, Angew. Chem., Int. Ed., 2014, 53, 7720; (b) V. Georgakilas, J. N. Tiwari, K. C. Kemp, J. A. Perman, A. B. Bourlinos, K. S. Kim and R. Zboril, Chem. Rev., 2016, 116, 5464; (c) L. Liao, H. Peng and Z. Liu, J. Am. Chem. Soc., 2014, 136, 12194.

12 Y. Hao, X. Wang, Y. Zheng, J. Shen, J. Yuan, A.-j. Wang, L. Niu and S. Huang, Electrochim. Acta, 2016, 198, 127.

13 (a) J. Schneider, M. Matsuoka, M. Takeuchi, J. Zhang, Y. Horiuchi, M. Anpo and D. W. Bahnemann, Chem. Rev., 2014, 114, 9919; (b) L. Wang and T. Sasaki, Chem. Rev., 2014, 114, 9455.

14 W. S. Hummers and R. E. Offeman, J. Am. Chem. Soc., 1958, 80, 1339.

15 O. A. Kholdeeva, T. A. Trubitsina, R. I. Maksimovskaya, A. V. Golovin, W. A. Neiwert, B. A. Kolesov, X. López and J. M. Poblet, Inorg. Chem., 2004, 43, 2284.

16 C. Su, M. Acik, K. Takai, J. Lu, S.-j. Hao, Y. Zheng, P. Wu, Q. Bao, T. Enoki, Y. J. Chabal and K. Ping Loh, Nat. Commun., 2012, 3, 1298.

17 S. Wang, L. Pan, J.-J. Song, W. Mi, J.-J. Zou, L. Wang and X. Zhang, J. Am. Chem. Soc., 2015, 137, 2975.

18 J. H. Kang, T. Kim, J. Choi, J. Park, Y. S. Kim, M. S. Chang, H. Jung, K. T. Park, S. J. Yang and C. R. Park, Chem. Mater., 2016, 28, 756.

19 T. Waters, R. A. J. O'Hair and A. G. Wedd, J. Am. Chem. Soc., 2003, 125, 3384. 